\title{
Modelling Team Effectiveness and its Determinants Among Multidisciplinary Engineering Students: A Case of Malaysian Public University
} \author{
$\operatorname{san}^{5}$ \\ ${ }^{1,2}$ Advanced Informatics School, Universiti Teknologi Malaysia \\ ${ }^{3}$ USBI-Sampoerna University, Jakarta, Indonisia \\ ${ }^{4,5}$ Advanced Informatics School, Universiti Teknologi Malaysia \\ *Corresponding Author E-Mail: Shawqi80@Gmail.Com
}

Shawqi Mohammed Hussein ${ }^{1 *}$, Salwani Mohd Daud², Teddy Mantoro ${ }^{3}$, Sya Azmeela Shariff ${ }^{4}$, Mahmudul Ha-

\begin{abstract}
Team effectiveness depends on the performance of each team member. Success or failure of a team highly relies on the interaction level of all members. Effective teamwork is a critical learning outcome for engineering students and it is one of the most desired skill required by employers. All engineering graduates must have the ability to function in multidisciplinary teams. Prior studies had also found that, many Malaysian employers agreed that the lack of team working skill among the Malaysian graduates would risk the survival of an organisation and in result developing low-level interpersonal skills which is equally necessary for working effectively in a team. However, in the engineering education literature most of the previous studies have focused on the area of professional environments. A very few studies were conducted in the context of educational environments to identify the factors that affect the team effectiveness in higher education. Moreover several internal and external factors also influence the outcomes of student teamwork and not every group is effective in their objectives and numerous groups fail. Therefore, this study is designed to identify the underlying factors that help students to develop their teamwork skill, thus improving team effectiveness. Hence, upon analysing the articles found in this study, nine (factors were identified to have more impacts towards team effectiveness, which were (1) team communication, (2) trust, (3) team cohesion, (4) team leadership, (5) team coordination and cooperation, (6) team commitment, (7) team performance, (8) team satisfaction, and (9) task interdependence. In addition, after comparing several models and theories, a conceptual model that demonstrates relationships among the identified factors was proposed. It asserted team performance and team satisfaction as the predictors of team effectiveness.
\end{abstract}

Keywords: Team Effectiveness; Team Performance; Multidisciplinary; Engineering Education; Teamwork.

\section{Introduction}

Team effectiveness research is a study of factors that influence a wide variety of team outcomes that meet or exceed the performance standard as well as maintain or enhance the capability of team members to work well in a team and the perceived satisfaction of individual team member's need $(1,2)$. It is a new attribute desired of graduates from both the engineering and computer science disciplines $(2,3)$. Prior studies examined the importance of teamwork and collaboration in science, technology, engineering, and mathematics (STEM) fields. According to Chen and Chong (4), engineering students are required to have both the professional engineering skills as well as soft skills such as communication, management, and teamwork skills. Association for Computing Machinery (ACM) also remarks to have teamwork skill for IT and computer science professionals. Meanwhile, all engineering graduates must have the ability to function in multidisciplinary teams (5). Previous studies on engineering graduates attributes also showed that Malaysian graduates lack the teamworking skills, such as contribution and cooperation (6), communication, and interpersonal skills (7-9) According to the Accreditation Board of Engineering and Technology (ABET), student team project is one of the early elements of developing professional skills at university level. Nowadays, many universities have integrated project based assignments in engineering courses to develop teamworking skill, which is quite common at undergraduate level (2) Several studies highlighted that the ability to work effectively in teams is a critical learning outcome for engineering students and it is one of the most desired skills required by employers $(5,10,11)$. ABET also outlines that engineering graduates from accredited programmes must have the ability to function in multidisciplinary teams(5). As many universities are striving to incorporate multidisciplinary team project into their curricula, research on effective teamwork in multidisciplinary teams is increasingly important (11).

Malaysia created a long term plan called Vision 2020 to develop a knowledge-based economy (KBE) and attain the status of a developed nation by 2020 (12). However to become a KBE-based country, Malaysia requires highly educated knowledge workers with good employability skills. Many Malaysian employers agree that Malaysian graduates lack of teamworking skill which would risk the survival of an organization and in result developing low-level interpersonal communication skill which is equally necessary for working effectively in a team (7).The Ministry of Higher Education (MOHE) Malaysia has developed a generic core module for 
the higher institutions to focus on developing employability skills among the students. Universiti Technology Malaysia (UTM) was one of the early institutions that outlined seven important employability skills comprising communication, teamworking, problem solving, adaptability, life-long learning, self-esteem, and ethics and integrity based on the generic modules provided by MOHE (7) . As observed in this context, it is genuinely sensible for higher institutions to put an extraordinary emphasis on teamwork skill as a part of each system's learning results. Moreover, several internal and external factors also influence the outcomes of teamwork (13, 14). However, not every group is effective in their objectives and numerous groups fail because of wrong team dynamics, lack of communication, and interpersonal clash among team members (15).

Though team effectiveness relies on several external and internal factors, limited studies were conducted in the context of educational environments to identify the factors affecting team effectiveness in higher education, in particular multidisciplinary engineering teamwork environment. Hence, this study was designed to fill this gap.

\section{Literature Review}

Engineering tests nowadays are becoming increasingly complex and need nothing less than multidisciplinary methods to overcome them. Engineers are anticipated to play a confident role and contribute well in a multidisciplinary environment. To achieve that, engineering programmes around the world have started to embrace multidisciplinary projects and courses into their curricula. The importance of taking a multidisciplinary approach to counter a silo approach is not only known in the field of engineering but also in supplementary fields (Masters et al. 2013).Sheridan, Evans (3) identified that multidisciplinary teams offered the richest informal learning opportunities to its followers and provided fast and creative solutions more often and with less struggle (16).

A study conducted by Bradley, Baur (17) found communication heads cohesion in time. Their findings were based on data collected at different time frames from 107 project teams, which supported the conclusions and the ordering of intermediate mechanisms from communication process to developing state cohesion. Barrick, Bradley (18) discussed that interdependence within teams controls the performance relationship method in small groups. High interdependence teams had higher team and following firm performance when the teams were more cohesive and had more communication. However, low interdependence teams had higher performance upon less communication and cohesion. An initial conceptual model of a team performance study showed that team interdependence controlled the relationship between team mechanism which included communication and cohesion and team performance. They also found all of the team constructs rely heavily on members' perception. Teams in this context need to rely on high level of team mechanism such as communication and cohesion among team members where teams should perform as working groups. So, based on the findings the importance of within team interdependence and act as a moderator between team interdependence and mechanism.

Dingsøyr, Fægri (19) reported that five constructs (team coordination, goal orientation, team cohesion, shared mental models, and team learning) were listed in team performance which highlighted parts that could be the focus of new practices and increase team productivity. The findings are important because they highlighted what effect practices should have, which could lead to increased understanding of why practices should be followed, and also the changes in how they are performed. Furthermore, the five constructs highlight the areas that could be the focus of new practices, which could further increase team productivity and performance.

Omar and Ahmad (20) investigated three input constructs which were team climate, work overload, and team leadership, project team effectiveness on research and measured by publication productivity, team member satisfaction, and job frustration Based on the study, it also examined the mediating effect of a process factor of team commitment. Findings suggested that different input constructs influence different aspects of team effectiveness and team climate is a key input factor that influences team effectiveness through team commitment as a process factor in an academic setting. Silva et al. (2016) reported the results of an investigation on the constructs that donate to team effectiveness in higher education. Task interdependence, task conflict, and personality traits appeared as key influences on team effectiveness. The empirical results from the study identified task interdependence as a critical factor in team effectiveness. Thus, task interdependence factor in this study offers a significant influence on team effectiveness in professional contexts. They also found that the link between team performances is affected by the mutual interaction among team members. In addition, personality traits are also considered as highly relevant in effective team performance. The results show that task interdependence is positively connected with team effectiveness.

Apart from the studies conducted before, several other studies had been conducted by other researchers. Yang and Jin (21) identified that social loafing was the top concern among members of both local and distributed teams. Social loafing is a team behaviour in which some team members do not contribute their fair share to the project. Pieterse and Thompson (22) and Chen and Chong (4) also described social loafing as a cause of conflict in student teams. Another work done by Borrego, Karlin (2) found that social loafing, interdependence, conflict, trust, and shared mental models are important constructs that affect team effectiveness in engineering context. In addition, some of the other constructs that affect team effectiveness were found by different authors, which are agreeableness (17), preassessment of teams and rewarding achievement by Figl (23), work overload (20), team discussion (24). It was also found that team prevention and promotion focused by Shin, Kim (25). Purna Sudhakar, Farooq (26) found that team climate, team diversity, team member competencies and characteristics, and top management support also affect team effectiveness.

\section{Methodology}

The goal of this study was to explore the factors affecting team effectiveness in team setting among multidisciplinary engineering environment. To identify previous articles which sufficiently focused on this topic, several academic databases were utilised such as Google Scholar, Emerald, ACM Digital Library, Taylor \& Francis Online, Science Direct, IEEE Explorer, and Web of Science. The literature search started with keywords and search terms For this study, the following keywords and strings were used as single word or in combination: factors AND team effectiveness*, determinants AND team effectiveness*, factors AND team performance*, determinants AND team performance*, factors AND team performance AND engineering project*, factors AND team effectiveness AND engineering project*, "factors influencing team effectiveness", "factors affecting team performance", "critical success factors of teamwork", "team effectiveness model", "team performance model", and "multidisciplinary engineering student project". Figure 1 shows the research framework of this study.

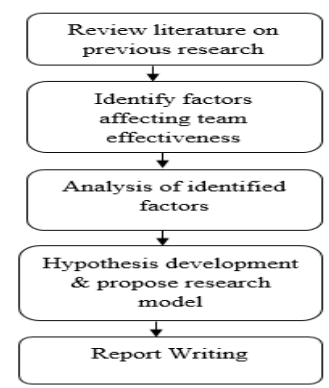

Fig. 1: Research framework

After reviewing previous researches, several factors were found to be contributing to team effectiveness in education and organisa- 
tional context such as team communication, trust, team leadership, cooperation \& coordination, shared mental models, team climate, task conflict, emotional intelligence, social loafing, team commitment, team learning, goal orientation, task interdependence, and team cohesion. However not all of them are suitable for engineering project. The following section discusses on the outcomes of the review.

\section{Results and Findings}

Upon analysing the related articles, nine factors were identified to have more impact based on their consensus that seem to be more relevant to team effectiveness in the context of this study as shown in Table 1. After comparing several models and factors, a conceptual model of team effectiveness was proposed. It asserted team performance and team satisfaction as the predictors for team effectiveness. Task interdependence was found to be a key influence and critical factor for team effectiveness in higher education (Silva et. al., 2016).

Table 1: Identified Constructs

\begin{tabular}{|l|c|}
\hline Factors & Frequency \\
\hline Team communication & 10 \\
\hline Trust & 8 \\
\hline Team cohesion & 8 \\
\hline Team leadership & 8 \\
\hline Team coordination \& cooperation & 6 \\
\hline Team commitment & 6 \\
\hline Team performance & 9 \\
\hline Team satisfaction & 5 \\
\hline Task interdependence & 3 \\
\hline
\end{tabular}

Team interdependence can be measured through task interdependence. Barrick, Bradley (18) reported that team interdependence controls the relationship between team mechanisms which are team communication, cohesion, and performance. It is also shown that communication heads cohesion in time (17) . In teams, communication is critical in providing, assessing, and synthesising team members' inputs. If members do not communicate, the unique ideas of each member will not be shared. Communication has remarkable effect on team performance (27). Prior studies found positive relationship between team cohesion and performance $(27,28)$. Hence this study included task interdependence, team communication, and team cohesion in the proposed conceptual model. Team leadership is another important construct that can affect team performance through team commitment (29-31). Team leader behaviour positively influences team member satisfaction (32). If team members have a negative perception about their team leader, they are likely to experience internal tensions, which may negatively affect team member satisfaction with the team (20). Team commitment motivates members to bind themselves to their team and devote effort on the team's behalf (30). Commitment is an important predictor for the team related behaviours performance. Other studies indicated direct relationship between team commitment and team performance $(30,33)$. Prior study also found that cohesion and satisfaction served as dual mediators of the trust-team effectiveness relationship (19) . Team satisfaction is defined as a project manager's perception on how team members feel about events within the project team which includes satisfaction with project works, satisfaction with team members, and satisfaction with being part of the project team. Likewise, there is a direct relationship between satisfaction and team performance (21). Hence this study also included trust which can be mediated by team cohesion and team satisfaction to maximise team effectiveness. Another study also found that trust had a direct effect on team satisfaction $(34,35)$ and performance $(35)$. The factor of team coordination and cooperation was also included as they could directly affect team performance $(15,36)$. Another study also reported an empirical evidence for direct relationship between team cooperation-coordination and team performance (37). Figure 2 shows the proposed conceptual model of team effectiveness.

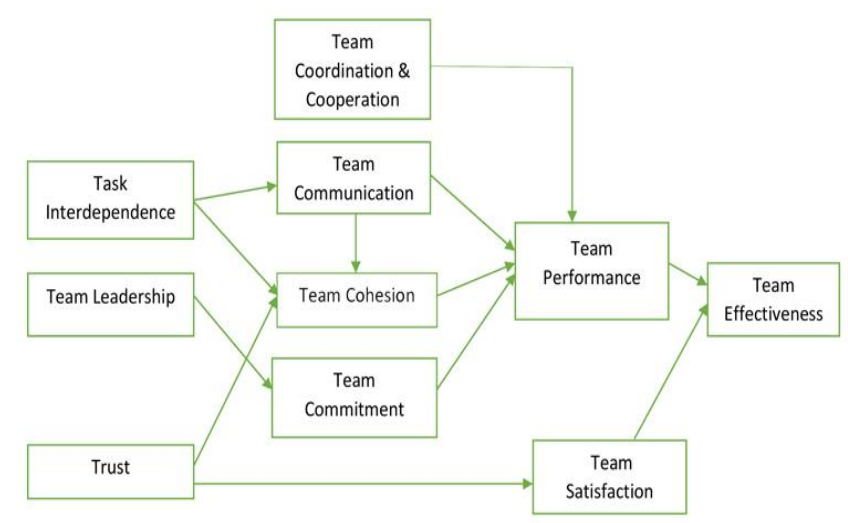

Fig. 2: A proposed conceptual model of team effectiveness

This proposed model also adopted I-P-O models to frame team effectiveness (2). Task interdependence, team leadership, and trust are considered as the input factors whereas team coordination \& cooperation, team communication, team cohesion, and team commitment are categorised as team process. According to the I-P-O model, input factors are the primary causes of a process, which in turn influence team outcomes (20) which are categorised as team performance, satisfaction, and team effectiveness. Based on the proposed conceptual model of team effectiveness, this study proposed the following hypotheses:

H1: A positive relationship can be observed between task interdependence and team communication.

$\mathrm{H} 2$ : A positive relationship can be observed between task interdependence and team cohesion.

H3: Team communication is positively associated with team cohesion.

H4: Team leadership has a positive impact on team performance through team commitment.

H5: Team coordination \& cooperation has a positive impact on team performance.

H6: Team commitment is positively associated with team performance.

H7: Team communication is positively associated with team performance.

H8: Team cohesion is positively associated with team performance.

H9: Trust has a positive impact on team satisfaction.

H10: Trust has a positive impact on team cohesion.

H10: Satisfaction has a direct and positive relation to team effectiveness.

H11: Team performance positively affects team effectiveness

\section{Conclusion}

This ongoing research has succeeded in identifying the determinants of team effectiveness among multidisciplinary engineering student teams. This study identified nine factors that affect team effectiveness. The outcomes of this study can be used by actual practitioners to improve team effectiveness or by fellow researchers to understand the relationship among these factors and team effectiveness. Higher institutions will be more aware to take these factors into account while incorporating teamwork as an educational technology which may significantly affect team effectiveness. Hypotheses were deduced rather than proving them empirically as it was beyond the scope of this paper. Hence, the next stage is to test this proposed conceptual model.

\section{Acknowledgement}

This research work was supported by Universiti Teknologi Malaysia. 


\section{References}

[1] Zarraga-Rodriguez M, Jaca C, Viles E. Enablers of team effectiveness in higher education: Lecturers' and students' perceptions at an engineering school. Team Performance Management. 2015;21(5/6):274-92

[2] Borrego M, Karlin J, McNair LD, Beddoes K. Team effectiveness theory from industrial and organizational psychology applied to engineering student project teams: A research review. Journal of Engineering Education. 2013;102(4):472-512.

[3] Sheridan PK, Evans G, Reeve D, editors. A PROPOSED FRAMEWORK FOR TEACHING TEAMEFFECTIVENESS IN TEAM-BASED PROJECTS. American Society for Engineering Education; 2012: American Society for Engineering Education.

[4] Chen C-Y, Chong PP. Software engineering education: A study on conducting collaborative senior project development. Journal of systems and Software. 2011;84(3):479-91.

[5] Main JB, Sanchez-Pena M, editors. Student evaluations of team members: Is there gender bias? Frontiers in Education Conference (FIE), 2015 IEEE; 2015: IEEE.

[6] Fagerholm F, Vihavainen A, editors. Peer assessment in experiential learning Assessing tacit and explicit skills in agile software engineering capstone projects. Frontiers in Education Conference, 2013 IEEE; 2013: IEEE.

[7] Ali MF, Joyes G, Ellison L. Building effective small-group team working skill through blended learning at Malaysia Tertiary Institution. Procedia-social and behavioral sciences. 2014;112:997 1009 .

[8] Zaharim A, Yusoff YM, Omar MZ, Mohamed A, Muhamad N, Mustapha R. Perceptions and expectation toward engineering graduates by employers: a Malaysian study case. WSEAS Transactions on Advances in Engineering Education. 2009;6(9):296-305.

[9] Singh GKG, Singh SKG. Malaysian graduates' employability skills. UNITAR e-Journal. 2008;4(1):15-45.

[10] Lingard RW. Teaching and assessing teamwork skills in engineering and computer science. Journal of Systemics, Cybernetics and Informatics. 2010;18(1):34-7.

[11] Rhee J, Parent D, Basu A. The influence of personality and ability on undergraduate teamwork and team performance. SpringerPlus. 2013;2(1):16.

[12] Qureshi M, Alshamat SA, Sabir F. Significance of the teamwork in agile software engineering. arXiv preprint arXiv:14086130. 2014.

[13] Channon S, Davis R, Goode N, May S. What makes a 'good group'? Exploring the characteristics and performance of undergraduate student groups. Advances in Health Sciences Education. 2017;22(1):17-41.

[14] Cumming J, Woodcock C, Cooley SJ, Holland MJ, Burns VE. Development and validation of the groupwork skills questionnaire (GSQ) for higher education. Assessment \& Evaluation in Higher Education. 2015;40(7):988-1001

[15] Alberola JM, Del Val E, Sanchez-Anguix V, Palomares A, Teruel MD. An artificial intelligence tool for heterogeneous team formation in the classroom. Knowledge-Based Systems. 2016;101:1-14.

[16] Tang SF, Logonnathan L. Taylor's 7th Teaching and Learning Conference 2014 Proceedings: Holistic Education: Enacting Change: Springer; 2015.

[17] Bradley BH, Baur JE, Banford CG, Postlethwaite BE. Team players and collective performance: How agreeableness affects team performance over time. Small Group Research. 2013;44(6):680711.

[18] Barrick MR, Bradley BH, Kristof-Brown AL, Colbert AE. The moderating role of top management team interdependence: Implications for real teams and working groups. Academy of Management Journal. 2007;50(3):544-57.

[19] Dingsøyr T, Fægri TE, Dybå T, Haugset B, Lindsjørn Y. Team performance in software development: research results versus agile principles. IEEE Software. 2016;33(4):106-10.

[20] Omar Z, Ahmad A. Factors Contributing to Research Team Effectiveness: Testing a Model of Team Effectiveness in an Academic Setting. International Journal of Higher Education. 2014;3(3):10-26

[21] Yang MC, Jin Y. An examination of team effectiveness in distributed and co-located engineering teams. International Journal of Engineering Education. 2008;24(2):400.

[22] Pieterse V, Thompson L, editors. A model for successful student teams. THE 36TH ANNUAL CONFERENCE OF THE
SOUTHERN

AFRICAN

COMPUTER

LECTURERS'ASSOCIATION (SACLA); 2006.

[23] Figl K. A systematic review of developing team competencies in information systems education. Journal of Information Systems Education. 2010;21(3):323

[24] Park G, DeShon RP. A multilevel model of minority opinion expression and team decision-making effectiveness. Journal of Applied Psychology. 2010;95(5):824.

[25] Shin Y, Kim M, Choi JN, Lee S-H. Does team culture matter? Roles of team culture and collective regulatory focus in team task and creative performance. Group \& Organization Management. 2016;41(2):232-65

[26] Purna Sudhakar G, Farooq A, Patnaik S. Soft factors affecting the performance of software development teams. Team Performance Management: An International Journal. 2011;17(3/4):187-205.

[27] Kasemsap K. Strategic business management: A practical framework and causal model of empowering leadership, team cohesion, knowledge-sharing behavior, and team performance. Journal of Social and Development Sciences. 2013;4(3):100.

[28] Salas E, Grossman R, Hughes AM, Coultas CW. Measuring team cohesion: Observations from the science. Human factors. 2015;57(3):365-74

[29] Sommer SA, Howell JM, Hadley CN. Keeping positive and building strength: The role of affect and team leadership in developing resilience during an organizational crisis. Group \& Organization Management. 2016;41(2):172-202.

[30] Rousseau V, Aubé C. The reward-performance relationship in work teams: The role of leader behaviors and team commitment. Group Processes \& Intergroup Relations. 2014;17(5):645-62.

[31] Markulis PM, Jassawalla AR, Sashittal H, Strang DR, Scipione P. The Effect of Team-Leadership Modes on Team Performance: A Preliminary Study. Developments in Business Simulation and Experiential Learning. 2014;33.

[32] Masters C, Baker VOT, Jodon H. Multidisciplinary, team-based learning: The simulated interdisciplinary to multidisciplinary progressive-level education (SIMPLEC) approach. Clinica Simulation in Nursing. 2013;9(5):e171-e8.

[33] Stephens CA. The moderating role of perceived organizational support and perceived supervisor support on the relationship between teamwork behaviors and affective commitment: San Jose State University; 2016.

[34] Romeike PD, Nienaber A-M, Schewe G. How differences in perceptions of own and team performance impact trust and job satisfaction in virtual teams. Human Performance. 2016;29(4):291309 .

[35] Braun S, Peus C, Weisweiler S, Frey D. Transformational leadership, job satisfaction, and team performance: A multilevel mediation model of trust. The Leadership Quarterly. $2013 ; 24(1): 270-83$

[36] Lee J, Lee J, Min J, Min J, Lee H, Lee H. Setting a knowledge boundary across teams: knowledge protection regulation for interteam coordination and team performance. Journal of Knowledge Management. 2017;21(2):254-74

[37] Pais L, dos Santos N, Mónico L, Fernandes N, Rebelo L, Figueiredo C, editors. Cooperation in Research Teams: An Exploratory factor analysis of the Organizational Cooperation Questionnaire. Proceedings of the SGEM Conferences on Social Sciences and Arts; 2014. 